\title{
France eyes role in US mission to retrieve rocks from Mars
}

[WASHINGTON \& MUNICH] France is considering taking part in a proposed US spacecraft expedition to collect samples of Martian rock and return them to Earth. France's participation, if it comes about, could greatly increase the scientific return of the mission, which is planned for the year 2005.

The idea of France launching the 2005 spacecraft on Europe's large Ariane 5 launcher in exchange for a significant role in the US Mars exploration programme has been discussed for several months by officials at the French Centre National d'Études Spatiales (CNES) and the US National Aeronautics and Space Administration (NASA). NASA's rules prevent it from buying a non-US launcher directly.

No agreement has been reached, but the NASA Administrator, Daniel Goldin, said last week that he is optimistic that the sample return mission would be collaborative. "It is my hope and expectation that we will do this with the French," he told a meeting of the American Astronomical Society meeting in Washington, DC.

NASA intends to launch spacecraft to Mars at every available opportunity for the occurring every 26 months. The current plan is to send landers equipped with rover vehicles to two different sites on the planet in 2001 and 2003.

Each rover would collect rock samples and 'cache' them for later retrieval. The 2005 lander would then be sent to the site deemed more scientifically interesting of the two, next decade or more, with launch windows

where it would pick up the cached samples and return them to Earth in 2008.

Because of NASA budget constraints, the 2005 spacecraft is scheduled to launch on a medium-size Atlas or Delta rocket. But the Ariane, with its much larger capacity, would almost double the amount of payload that could be delivered to Mars. France could decide to use this excess capacity to send a lander to the second sampling site, according to Daniel McCleese, chief scientist for Mars exploration at NASA's Jet Propulsion Laboratory in California.

A full Ariane 5 launch would cost CNES about Ecu150 million (US\$160 million. Other, cheaper alternatives for France include providing the Mars-orbiting vehicle that receives samples from the surface.

The country could also add scientific instruments to the 2005 rover - currently designated to be a 'dumb' rover that simply fetches samples collected on earlier missions. Adding the ability to analyse and collect its own rocks would provide a backup in case the rover is unable to retrieve the cached samples, says McCleese.

Francis Rocard, who heads the Solar System exploration office at CNES, says that if France were to furnish an Ariane launch, it would want to be involved in "some key elements" of NASA's Mars programme in return. This would probably include participation in the 2001 and 2003 missions, as well as the 2005 sample return, he says.

NASA has already chosen the scientific payload for the 2001 mission, but French sci-

\section{French inquiry to look into thesis fraud}

[PARIS] France's Atomic Energy Commission (CEA) and the Centre de la Recherche Scientifique (CNRS) have jointly set up a panel of inquiry to investigate the circumstances surrounding the apparent fabrication of data in a doctoral thesis by a young graduate student, and the 'structural factors' that initially allowed the fraud to take place.

The situation concerns a researcher who appears to have manipulated her results to make them correspond to the conclusions she was seeking. Although doubts had arisen over the quality of her data when she presented her thesis, she was still recruited by the CEA as a postdoctoral researcher.

Several months later, however, it became clear that some of the data had been fabricated. The researcher - who has not been named - was removed from her post, and two publications in which the results appeared are now under review.

Catherine Cesarsky, director of the department of science of matter at the CEA, says that this is the first clear example of scientific fraud she has come across. She adds that it is "very rare" for students in her department to be left alone to work on data, as most work in large teams, making fraudulent activity virtually impossible.

But the CEA now faces the question of how the student was able to publish her results, obtained while she was working in a laboratory run jointly with the CNRS, and include them in her thesis. This will be one of the main questions to be addressed by the inquiry. "We want to reassure ourselves that a student is never again left with data that no-one else has checked," says Cesarsky. The panel will report within six weeks. Eric Glover

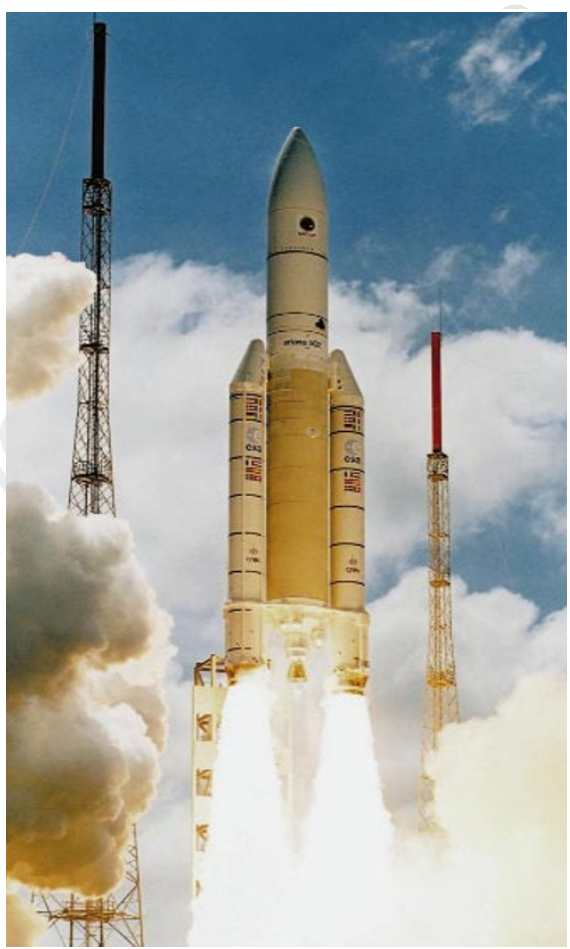

Capacity booster, Ariane 5 seen here at its first launch last October, would double the payload that could be sent to Mars.

entists could be added as co-investigators, says Rocard. The 2003 payload, which has yet to be selected, could also include French experiments.

CNES has asked Germany to join the collaboration should an agreement with NASA be signed. It is likely that German scientists would contribute to the instrumentation but Germany's space budget is currently too tight to make a large involvement likely.

CNES scientists have long had an interest in Mars. The agency sponsored several experiments on the Russian Mars 96 spacecraft that failed two years ago before reaching the planet. French investigators are especially strong in the areas of imaging spectroscopy and micro-seismometers for planetary surface studies, according to McCleese.

International participation would strengthen NASA's Mars programme, he says, and is of particular interest to Goldin. Working groups from CNES and JPL have been meeting regularly to identify technical opportunities for collaboration, while the French government is working out budgetary issues. Both McCleese and Rocard hope for agreement by this summer.

The discussions come at a time when the European Space Agency's own proposed Mars mission, called Mars Express, faces uncertain funding (see Nature, 390, 325; 


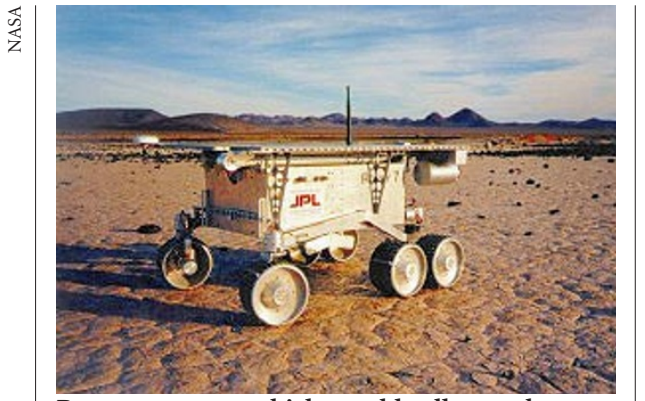

Rover returns: a vehicle would collect rock samples to be brought back to Earth.

1997). CNES has been encouraged by French research minister Claude Allègre — himself a geologist who took part in analysis of the moon rocks - to play a large and consistent role in the international Mars programme and to do so it is prepared to forge significant bilateral agreements. This is a situation that secretly worries the ESA considerably, since bilateral agreements inevitably compete for national funding with scientific instruments for ESA missions.

Mars Express, a lander/orbiter mission scheduled for launch in 2003, may also include international collaboration. ESA and NASA have been discussing an Italian idea whereby a communications link on the Mars Express spacecraft would be used for the US sample return mission in 2005. So far, however, no agreements have been signed.

CNES and NASA are farther along in discussing what McCleese calls joint "precursor mini-missions" to Mars, which would be piggybacked on Ariane 5 launches that deliver commercial satellites to high geostationary orbits. These missions, which would run in addition to NASA's already planned Mars programme, could deliver between 80 and $160 \mathrm{~kg}$ of payload to the Martian surface beginning as early as 2000 .

France would provide the Ariane 5 piggyback ride and an upper stage rocket, while NASA would provide the spacecraft. The scientific instruments would be developed jointly. Each mission would cost between $\$ 25$ million and $\$ 50$ million, and would be able to land simple instruments such as small probes or penetrators on the surface of Mars.

McCleese says the mini-missions would be ideal for positioning networks of sensors that could collect seismological and meteorological data. "It's something we've been working on for 20 years," he says.

US funding for these mini-missions would have to come out of NASA's existing Mars programme, which is budgeted at about $\$ 1$ billion over 10 years. The missions might also be accommodated within the agency's Discovery line of small and inexpensive planetary missions. As with collaboration on the sample return, no agreement has been reached yet. But McCleese believes the mini-missions have "a very high probability of happening".

Tony Reichhardt

\section{Quebec says yes to federal money for infrastructure}

[MONTREAL] The separatist government of the Canadian province of Quebec has bent its sovereignty principles to gain access to some of the C\$800 million (US\$560 million) of research infrastructure funding being offered by the federal government.

But the move has not been made without protest. And it remains unclear how far the province is likely to go in imposing what it has described as its own priorities on the way the money is used.

The funds are being made available through the Canada Foundation for Innovation (CFI), which was set up last year in the federal budget using money released as a result of a tight fiscal policy (see Nature 385, $759 ; 1997)$. It was hoped that the funds would help to attract back to the country Canadian researchers working abroad.

Project proposals were invited from universities and hospitals across the country, but Quebec's education minister, Pauline Marois, condemned this in December as an example of federal intrusion in a provincial jurisdiction.

Education and the administration of health services are provincial responsibilities in Canada (although these are not the only areas in which Quebec frequently complains about federal intrusion). Marois demanded that Quebec's share of the C $\$ 800$ million be handed directly to the province, and even threatened to penalize institutions that might respond to the CFI's invitation.

When the federal government saw the contradiction in Quebec policy, its industry minister, John Manley, sent a letter to Marois and Quebec's health minister Jean Rochon accusing the province of playing petty politics.

At a news conference, Quebec's intergovernmental affairs minister, Jacques Brassard, revealed his government's underlying philosophy when he described the "ideal situation" as being able to say to the federal government: "It's none of your business. We don't want you in Quebec and we don't want your money."

But Brassard added that sometimes it is necessary to be pragmatic. A modified procedure has now been developed under which Quebec universities and hospitals will submit their projects to the CFI through the Quebec government.

One reason for Quebec's stance is that like the other provinces - it will have to pay overhead costs, and perhaps provide matching funds, for any projects funded by the CFI. For some years, all provinces have suffered drastic cuts in federal transfer funds in education and health fields.

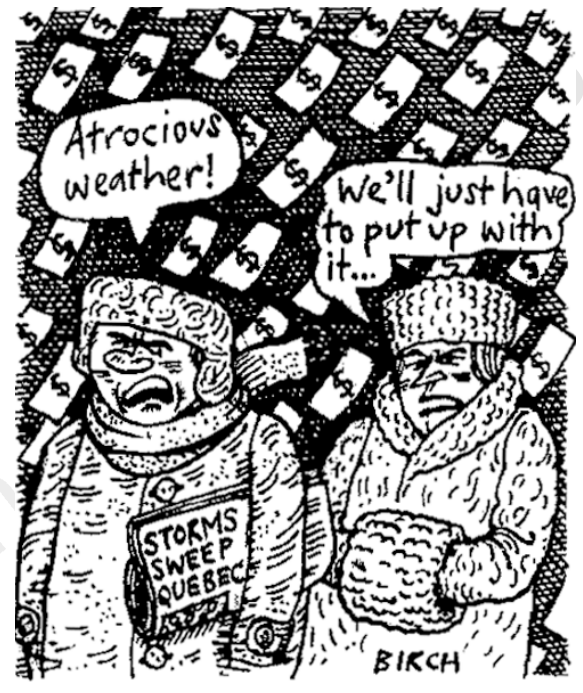

Denis Gagnon, acting president and chief executive officer of CFI, says that, like many researchers, he was greatly disappointed by the initial stance of the Quebec government.

He says Quebec came to the press conference at which Brassard made his comments with both a political issue and an operational issue. "The political issue I have nothing to do with," said Gagnon. "It's between governments."

He admits that all provinces are concerned about the question of operating costs, and will be meeting their representatives in the next few weeks to talk about the issue.

"I will be discussing with the provinces what we want to do and how we could work together in such a way that we will fund what they want."

Gagnon thinks it unlikely that the provinces will seek to impose their own priorities on research institutions, and is keen to receive applications that have the support of these governments as well as their institutions. But he admits he does not know how this might come about.

For example, Quebec might ask its own two fund-granting institutions, or some sort of committee, to consider the applications before they go to the CFI.

Gagnon says it is unclear what the Quebec government meant when it said that applications should accord with "our priorities".

"It's clear from the original funding agreement between CFI and the federal government that we would like to have the universities and hospitals establish their [own] priorities, and then tell us what they are," he said. "My feeling is that this is what will happen."

David Spurgeon 